\title{
MANAGING SUSTAINABILITY FOR COMPETITIVE ADVANTAGE: EVIDENCE FROM THE HOSPITALITY INDUSTRY
}

I. Gutiérrez, J.M. Alcaraz, L. Susaeta, E. Suárez, José Ramón Pin, 


\title{
MANAGING SUSTAINABILITY FOR COMPETITIVE ADVANTAGE: EVIDENCE FROM THE HOSPITALITY INDUSTRY
}

\author{
I. Gutiérrez¹, J.M. Alcaraz², L. Susaeta ${ }^{3}$, E. Suárez, José Ramón Pin ${ }^{5}$
}

\begin{abstract}
The hospitality industry "is in the midst of a sustainability awakening" (Prairie, 2012). Many hospitality managers seem to be willing to adopt sustainability practices in order to obtain a competitive advantage. In this paper we use Barney's VRIO framework (value, rareness, imitability and organization) to examine the role of resources or capabilities in developing and maintaining competitive advantage through the development of sustainability practices in the hospitality industry.

The article reports the findings from interviews conducted with 17 hospitality managers from hotels established in Mexico and recognized as champions in sustainability. These results contribute to a better understanding of the factors that determine competitive advantage in the hospitality industry. Furthermore, the results have strong practical implications regarding the implementation of sustainability strategies.
\end{abstract}

Keywords: Sustainability; Competitive advantage; Resource-based approach

\footnotetext{
1 Professor, Universidad de Las Américas

2 Senior Lecturer, Murdoch Universiy

3 Senior Lecturer, UCM

4 Professor ESIC

5 Professor of Managing People in Organizations and Business Ethics José Felipe Bertrán Chair of Governance and Leadership in Public Administration IRCO - International Research Center on Organizations, IESE
} 


\section{MANAGING SUSTAINABILITY FOR COMPETITIVE ADVANTAGE: EVIDENCE FROM THE HOSPITALITY INDUSTRY}

\section{Introduction}

The literature shows several examples of how sustainability is linked with competitive advantage (Porter and Kamer, 2006; Branco and Rodrigues; Falkenberg and Brunsael; 2011). In the tourism industry, environmental and social pressures push organizations to get involved in sustainability (Simão, 2010). Leading global companies in the hospitality industry have included sustainability plans in their corporate strategies. Most of them try to show their commitment to sustainability in order to enhance their competitive advantage, to build a brand and to differentiate from their competitors (Jones, Hillier and Comfort, 2014). However, empirical studies indicate that results regarding the relationship between sustainability and performance are mixed (Porter and Kramer, 2006; Falkenberg and Brunsael; 2011). The literature indicates that this relationship can be studied effectively using Barney's VRIO framework (valuable, rare, imperfectly imitable and organized) (Barney, 1991; Barney, 1995; Barney and Wright, 1997; Barney et al., 2012; Peng, 2013) including outcomes related to competitive advantage, because the analysis of internal resources, for the most part, explains why sustainability is not always a synonym for competitive advantage (Falkenberg and Brunsael, 2011).

Studies mobilizing the resource-based approach rarely focus on sustainability issues (Tavitiyaman, Qu and Zhang, 2011; Barney, Della Corte, Sciarelli and Arikan, 2012). Sometimes, they are just theoretical studies (Branco and Rodrigues, 2006). Existing empirical studies do not analyze internal resources in the way the VRIO framework suggests (Simão, 2010).

This article contributes to the hospitality management literature by enlarging the limited empirical research about hospitality strategic management topics and sustainability (Harrington, Chathoth, Ottenbacher and Altinay, 2014). As we stated before, studies including hospitality, sustainability and the VRIO framework do not exist in the present literature. In addition, to our knowledge, empirical studies about this subject focused on countries outside North America and Europe remain scarce. 
Drawing on Barney's VRIO framework (Barney, 1991; Barney, 1995; Barney and Wright, 1997; Barney et al., 2012; Peng, 2013) and the results of empirical work integrating 17 interviews carried out in Mexico, we contend that, in terms of sustainability strategies, the management of internal resources plays an important role in obtaining a sustained competitive advantage.

This paper is organized as follows: first, a literature review is presented regarding sustainability and competitive advantage in the hospitality industry, and significant research gaps in this respect are put into evidence. We also develop a conceptual framework following a resourcebased approach and using the VRIO framework (value, rareness, imitability and organization). Next, the research methodology is described. Then, the results of our study are explained. Finally, we present a discussion and conclusion section. In this section, we include some of the implications in terms of strategic management; the limitations of the study are also outlined and we suggest future research directions.

\section{Literature Review}

\section{Sustainability in the Hospitality Industry}

Sustainability is described in the literature with different approaches. Some scholars consider that sustainability in organizations refers mostly to an ecological concern or to a social responsibility issue (Linnenluecke and Griffiths, 2010). Several studies described three overlapping dimensions of sustainability (economic growth, social equity and environmental protection. The intersection between these three dimensions will produce a sustainable system if it is economically equitable, socially bearable and environmentally viable (United Nations General Assembly, 1987; Adams, 2006; Todorov and Marinova, 2009). Others works consider that sustainability arises as an answer the interests of a variety of stakeholders: shareholders, suppliers, customers and society (Jones et al., 2014). The idea that sustainability arises from normative principles that respond to questions about how we live and how we might live is also present in the literature. These principles are inherent in political decisions that motivate sustainability development (Amsler, 2009). Summarizing previous arguments, we suggest that sustainability refers to the integration of environmental principles, social concerns and economic development into an organization, satisfying the needs of stakeholders.

The literature indicates that sustainability is becoming more and more important in the tourism industry because of the mix of products and services that are offered and the environmental, economic and social pressures involved in the industry (Simão, 2010).

For several leading hotels chains, sustainability is integrated into their corporate strategies and supports the growth of their businesses (Jones et al., 2014). Indeed, communication of a commitment to sustainability can bring several positive outcomes for organizations, which will enhance their competitive advantage: "higher levels of customer satisfaction and loyalty; improved company, brand and product reputation; more motivated and productive employees; better relations with the local community and public authorities; and increased cost savings" (European Commission, 2009: 4). Results of an exploratory study analyzing the corporate websites of 10 leading hotels chains shows that all of them report their sustainability initiatives. Some of the hotel chains include formal sustainability reports, whereas others provide more limited information. However, all of them include evidence of their environmental, social and economic agendas (Jones et al., 2014). 
Although there are many benefits from sustainability (Porter and Kramer, 2006; European Commission, 2009), it was reported that sustainability does not always lead to a strategic advantage for organizations (Porter and Kramer, 2006). Attributes of firm resources may lie at the origin of the mixed results regarding sustainability in empirical studies (Falkenberg and Brunsael; 2011). Using a resource-based approach, several research efforts attempt to explain how sustainability influences the performance of firms (Barney, Wright and Ketchen, 2001; Branco and Rodrigues, 2006; Falkenberg and Brunsael; 2011). This theoretical approach is particularly relevant, because it acknowledges the important role of concepts such as knowhow, corporate culture and reputation over performance (Russo and Fouts, 1997).

In the hospitality industry, the resource-based approach has been applied mostly to understand, for example, the strategic importance of technology innovation, advertising, service quality management or niche marketing (Tavitiyaman, Qu and Zhang, 2011). Recent works focus on that management of resources as an essential component of sustainable tourism development. However, most of them emphasize contextual resources, such as climate, beaches, hotel support and cultural services (Simão, 2010) and do not explore the internal resources of firms.

This study aims to address the research gaps identified in the literature, regarding studies about sustainability in the hospitality industry. First, there is limited research concerning hospitality strategy topics. Furthermore, those studies focus mainly on the context of the United States and the United Kingdom, and less than $0.3 \%$ of research topics in hospitality include sustainability issues (Harrington, Chathoth, Ottenbacher and Altinay, 2014). This lack of research integrating sustainability in the hospitality industry is surprising because, as we stated before, sustainability is becoming an important issue in the hospitality industry (Jones et al., 2014). Second, this study will explore the importance of internal resources for hospitality firms adopting sustainability, making it different from most existing studies (Simão, 2010; Tavitiyaman et al., 2011; Barney et al., 2012). Third, following Barney (1995), Barney and Wright (1997), Barney et al., (2012) we wish to understand how sustainability can produce a competitive advantage for a firm by applying Barney's VRIO framework; to our knowledge, this has not been covered in the current literature. The following section describes the VRIO conceptual framework used in this research.

\section{Conceptual Framework}

A resource-based approach focuses on the resources available to a firm as the root for obtaining a competitive advantage. Under this approach, the firm is considered as a heterogeneous and unique bundle of resources and capabilities that are a determining factor in firm performance (Grant, 1991; Barney, 1991; Barney, 1995; Barney, 1997; Barney, and Wright, 1997; Russo and Fouts, 1997; Barney et al., 2012; Peng, 2013).

Following Barney (1991:101), a firm's resources “include assets, capabilities, organizational processes, firm attributes, information, knowledge, etc. controlled by a firm that enable the firm to conceive and implement strategies that improve its efficiency and effectiveness." There are three basic categories of resources that can be sources of competitive advantage: physical capital resources, human capital resources and organizational capital resources. (Barney, 1991; Barney and Wright, 1997; Peng, 2013). Firm plants, equipment, manufacturing facilities, technology, geographic location and finance are considered as physical capital resources. Skills, training, experience, judgment, risk-taking propensity, intelligence and wisdom of firm's employees are human capital resources. A firm's structure, history, organizational culture, 
planning, human resources and coordinating systems are included in organizational capital resources (Barney, 1991; Barney, 1995; Barney and Wright, 1997; Barney et al., 2012, Peng, 2013).

Academics acknowledge that not all the resources are strategically significant. A resource could be a source of sustained competitive advantage if it has four attributes: valuable, rare, imperfectly imitable and organized (Barney, 1991; Barney, 1995; Barney and Wright, 1997; Barney et al., 2012, Peng, 2013). These attributes constitute the VRIO framework as established by Barney (1995). We offer a brief description of the attributes comprised in this framework in the following paragraphs.

Value. Resources must create value for the firm. They need to add value for the firm, enabling the firm to recognize opportunities and neutralize threats. Valuable resources are at the foundation of internal sources of a firm's competitiveness. To be valuable, resources must allow the firm to differentiate, to decrease costs or increase revenues, or to be aligned with the sector's key factors of success (Amit and Shoemaker, 1993). In addition, firm resources need to add value over time, despite changes in the competitive context. Some characteristics of valuable resources could be linked to experience, specific technological/manufacturing skills, quality, a high-status reputation, creativity and innovation (Barney, 1991; Barney, 1995; Barney and Wright, 1997; Barney et al., 2012, Peng, 2013).

Rareness. To be a source of competitive advantage, firm resources must be rare. They should not be widely available or possessed by numerous competing firms. If a firm's resources are valuable and rare, they may enable the firm to obtain at least a temporary competitive advantage. Exploitable resources that are different from the competition, unique inventory control systems, and unique leadership characteristics could be examples of rare resources (Barney, 1991; Barney, 1995; Barney and Wright, 1997; Barney et al., 2012, Peng, 2013).

Imitability. To provide competitiveness, resources of the firm must be difficult to imitate. The resources may be difficult to imitate due to a combination of three reasons: a) the resources were acquired or created under the conditions of a particular historical situation; b) the development, nurturing and exploitation of the resources depends on small decisions rather than on bigger decisions; and c) the resources are part of a socially complex situation. Valuable, rare and difficult to imitate resources can lead a firm to a strategic advantage. The owners' managerial values, managerial idiosyncrasies, the organizational culture, teamwork, trust, friendship and employee attitudes are difficult to imitate (Barney, 1991; Barney, 1995; Barney and Wright, 1997; Falkenberg and Bunsael, 2011; Barney et al., 2012, Peng, 2013).

Organization. In order to obtain a competitive advantage, a firm must be organized with policies and procedures directed at exploiting resources. Firm resources that are rare, valuable, difficult to imitate and organized can provide a sustained competitive advantage (Barney, 1991). Appropriate formal structures, control systems, and HR policies and practices are some examples of a firm's organization (Barney, 1995; Barney and Wright, 1997; Barney et al., 2012, Peng, 2013). 


\section{MethodS}

To perform the empirical study, we conducted 17 interviews with hotel managers from 11 hotels established in Mexico. Interviewees were selected from hotels recognized as champions in sustainability (Table 1). Semi-structured interviews were conducted face to face, by telephone and via Skype between March and November 2012. In 2014, between February and July, a second round of interviews took place to request specific information for the development of this paper. In general, participants were asked about five topics: 1) sustainability and competitive advantage; 2) priorities of the company with regard to sustainability; 3) the role of HRM in sustainability; 4) the embeddedness of sustainability in organizational culture; and 5) the measurement, impact and challenges of sustainability in the organization. The interviews ranged from 40 minutes to one and a half hours in length.

\section{Table 1}

List of hotels and persons interviewed

\begin{tabular}{|c|c|c|}
\hline Interviewee code & Position of Interviewee & Awards \\
\hline 1-CEP & General Manager & LEED (Leadership in Energy and Environmental Design) \\
\hline 2-MMR-a & $\begin{array}{l}\text { Human Resources } \\
\text { Manager }\end{array}$ & \multirow{2}{*}{$\begin{array}{l}\text { Biospheres, Hoteles Verdes (SEMARNAP), Hydro- } \\
\text { sustainable Hotel }\end{array}$} \\
\hline 2-MMR-b & Quality Manager & \\
\hline 3-MPPP-a & $\begin{array}{l}\text { Human Resources } \\
\text { Manager }\end{array}$ & \multirow[t]{2}{*}{ EarthCheck, Hoteles Verdes (SEMARNAP) } \\
\hline 3-MPPP-b & Certification Manager & \\
\hline 4-GPVRS-a & Training Manager & \multirow{2}{*}{$\begin{array}{l}\text { EarthCheck, Hoteles Verdes (SEMARNAP), Mesoamerican } \\
\text { Reef Tourism Initiative (MARTI), ECPAT International. }\end{array}$} \\
\hline 4-GPVRS-b & $\begin{array}{l}\text { Quality and Sustainability } \\
\text { Manager }\end{array}$ & \\
\hline 5-BH-a & $\begin{array}{l}\text { Human Resources } \\
\text { Manager }\end{array}$ & \multirow{2}{*}{$\begin{array}{l}\text { EarthCheck, Empresa Limpia (PROFEPA), Hoteles Verdes } \\
\text { (SEMARNAP) }\end{array}$} \\
\hline 5-BH-b & Controller Manager & \\
\hline 6-FAM & $\begin{array}{l}\text { Engineering and } \\
\text { Maintenance Manager }\end{array}$ & $\begin{array}{l}\text { Empresa Limpia (PROFEPA), Hoteles Verdes } \\
\text { (SEMARNAP) }\end{array}$ \\
\hline 7-RC & General Manager & Rain Forest Alliance, Hoteles Verdes (SEMARNAP) \\
\hline 8- FIPF-a & $\begin{array}{l}\text { Human Resources } \\
\text { Manager }\end{array}$ & \multirow{2}{*}{$\begin{array}{l}\text { Empresa Limpia (PROFEPA), Punto Limpio, Hoteles Verdes } \\
\text { (SEMARNAP) }\end{array}$} \\
\hline 8- FIPF-b & Maintenance Manager & \\
\hline 9-ROOP & $\begin{array}{l}\text { Human Resources } \\
\text { Manager }\end{array}$ & EarthCheck \\
\hline 10-HIF & Training Manager & Empresa Limpia (PROFEPA) \\
\hline 11-HMM-a & $\begin{array}{l}\text { Human Resources } \\
\text { Manager }\end{array}$ & \multirow{2}{*}{ EarthCheck, Rain Forest Alliance } \\
\hline 11-HMM-b & $\begin{array}{l}\text { Social Responsibility } \\
\text { Manager }\end{array}$ & \\
\hline
\end{tabular}




\section{Results}

Barney's VRIO framework based on four resource attributes is used for presenting the results of the empirical study (Barney, 1991; Barney, 1995; Barney and Wright, 1997; Barney et al., 2012, Peng, 2013).

\section{Value}

Several valuable resources and capabilities related to sustainability are present in hospitality industry firms. In some hotels we can observe that sustainability is inherent to their business strategy (CEP, BH-a): "Our marketing strategy is oriented to be considered as an environmental friendly hotel, a completely green hotel” (BH-a). Sustainability appears to lead firms to obtain a competitive advantage in terms of differentiation or cost. That is why it is very important for hotels to be involved if they want to gain or retain clients who are interested in sustainability (FIPF-a; FIPF-b, FAM, HMM-b, HIF, BH-a, BH-b, MPPP-b, MMR-a, MMR-b, ROOP, GPVRS-a, GPVRS-b, RC, CEP): "Environmental certification is generally asked for special segment of clients... for some firms from foreign countries it is mandatory for us to have that certification if we want to sign a commercial contract with them... That gives us an advantage over other hotels" (FIPF-a). First, sustainability helps hotels to earn a top position in their clients' minds: "In the hotel industry we are considered as an environmental leader. All the processes involved about sustainability make us more productive; as a result we are considered as the number one chain in Mexico" (FAM). Second, it helps them to be more competitive: "Clients' perceptions about our involvement in sustainability make us more competitive in comparison with another firm that is not involved in or...not working on sustainability issues" (HMM-b). Certificates obtained regarding sustainability issues seem to be very valuable: "We know that we have a competitive advantage because there are few hotels that have all the certificates and prizes that we have in terms of sustainability" (GPVRS- a). Clients are also informed of hotel engagement in sustainability because they can see the sustainable certificates at the hotel's entrance and in the card room (FIPF-a, FIPF-b, MPPP-a, MMR-b, GPVRS-a, GPVRS-b). Hotels are listed on the website "Hoteles Verdes" (Green Hotels), Earth Check, or LEED (FAM, BH-a, GPVRS-a, GPVRS$\mathrm{b}, \mathrm{RC}, \mathrm{CEP}$ ) and the hotels' commitment is recognized in newspapers (FAM).

For interviewees (FIPF-a, FIPF-b, FAM, HMM-a, BH-a, BH-b, MPPP-b, MMR-a, MMR-b, GPVRS- $a$, GPVRS-b, RC, CEP), sustainability also enables firms to reduce costs, giving them economic advantages over other firms: "With the savings made, our company can reduce costs, so we can invest much more and we can be more competitive" (FIPF-b). "Being involved in sustainability has resulted in important savings in energy and water consumption" (HMM-a).

Firms involved in sustainability have developed expertise and specific skills that are valuable for clients, workers and society (CEP, BH-b, ROOP): "From the garbage of the hotel we decided to prepare compost...We are now in our third generation of compost...We offer compost to clients and they love it" (CEP). A hotel's commitment to sustainability is also valuable because it responds to a demand for solutions to environmental problems (BH-b, ROOP, CEP): "For many years we have been involved in beach cleaning and reforestation... We have the support of clients and families from the community" (BH-b). 


\section{Rareness}

Being involved in sustainability per se is not rare. For some firms it is a strategic necessity because of regulatory laws and because it is a socially acceptable behavior (Simão, 2010). However, firms that are really devoted to sustainably are scarcer. The characteristics of leaders reflect the degree of a firm's commitment, constituting a potential source of competitive advantage. Leaders who are truly committed and passionate about sustainability are difficult to find (HMM-b, HIF, CEP, GPVRS-a, FIPF-a): "The firm has always been concerned with helping, I think this mindset comes from the CEO, because he is always looking to employees' health, comfort, and what they need. He also makes sure that guests have what they need. So, his mentality permeates us: we are always thinking about how we can help, how we can serve others: employees, clients or society. This ideology of service is so strong that it drives us. Everything we do is helping, helping, helping, and that becomes the basis of our business and comes from the foundation: our CEO... We are so involved in sustainability because of him, because of his leadership. A few days ago we went to visit a rehabilitation center for children and nobody complained about it. Everybody was saying: I want to help. How I can help? This type of behavior is something unusual, because in my experience in most firms employees think that this kind of visit is a waste of time" (HIF).

Interviewees agree about the importance of good leadership involved in sustainability to ensure commitment from employees (MPPP-a, MPPP-b, MMR-a, GPVRS-a, RC, FIPF-a, HMM-a, HMMb, HIF, CEP, FAM, BH-a, BH-b): "The most important is that all the managers must be committed seriously to sustainability. If sustainability is not in managers' mindsets, employees are not going to follow. We have to make our employees aware of how doing the right things at work and at home could help the planet and society" (FIPF-a). In addition to generating commitment in other people, leaders must ensure that employees are aware of what they are doing and why it is important, and they must provide follow-up in terms of sustainability. Leaders must be the first in the hotel to be convinced about sustainability (FAM, FIPF-b, GPVRS-a, HMM-a, HMM-b, CEP, BH-a, BH-b): "If a leader considers sustainability to be a waste of time, it is more difficult for employees to believe it is important" (FIPF-b). Then, the role of the leader becomes crucial: "Leaders have to pass that baton to employees. We have to work with them, encourage them to do the activities... I think all that contributes to the success of sustainability. Without employee's engagement, we would do nothing. So, implementing awareness activities and leading by example are fundamental; we cannot be in sustainability without support, conscience and commitment from employees, and that's why a good leader is so important” (BH-a).

A leader must also be able to develop strategies to involve employees in sustainability efforts (FAM, FIPF-b, GPVRS-a, HMM-b, CEP, BH-a, BH-b): “As the person responsible for sustainability in the firm, I have to prepare and to cook the information in order to make it more digestible for the receiver. I need to have a strategy to make our employees aware of sustainability. I need to make sure they are aware, make them able to give ideas, implement actions, give them incentives and motivate them. They need to see the benefits. If you don't believe in what you are selling, nobody is going to purchase you" (HMM-b). 


\section{Imitability}

Resources or capacities that are costly to imitate generate competitive advantage. For the hotels under study, particular history and socially complex resources seem to be a source of inimitability.

Concerning particular history, some hotels were created under a sustainable perspective because of an awareness of the consequences of pollution in the environment (RC, CEP): "After several years living in another city where we observed how the petroleum industry contaminates everything, we decided to move here and build the hotel in a sustainable way. Even if we are in a tourist area where hotels are trying to maximize the area dedicated to hotel rooms under a strong geographical constraint, at the hotel from the beginning we took care to have sufficient green areas. From the sky you can identify the hotel because of the green area: it is like a small jungle in the midst of a bustling city. We also think about the optimal utilization of natural resources. For example, we think about swimming pool water for use of the WC and in this way we are able to reuse the water. We also have solar water heaters throughout the hotel; we recollect rain water for watering gardens and now we are trying to use wind energy for the hotel. All this means that the hotel has very little impact on the environment" (RC). In the particular case of RC, the hotel supports (office and logistics) the Mayab Ecologist Group (GEMA Group), an environmental non-governmental organization, and one organization that runs animal shelters. As part of its activities, the hotel supports the urban community with courses, workshops and conferences that are held once a week to talk about human development, relaxation and personal motivation. Activities to preserve indigenous traditions from various parts of Mexico, especially the Nahuatl and Maya traditions, are also carried out.

Other hotels were created after natural disasters in order to help the people from local communities who lost everything (HMM-a, HMM-b): "These hotels were born with a socially responsible vision. In 2002, there was a strong hurricane in the entire Yucatan Peninsula called Isidore. This hurricane devastated the whole area; this led to new hotels... and a foundation to better support the community" (HMM-b). HMM hotels created a foundation that supports the community in several aspects. Since its launch, the hotel has trained 554 people in human and organizational development issues to enhance productivity. Craft cooperatives supported by the hotel between 2005 and 2011 have generated an income of roughly \$860,000 and Spa cooperatives have earned an income in the same period of approximately $\$ 2.5$ million. In the area of education, the hotel has developed eight community libraries with 1,873 beneficiaries. In terms of health care, with the support of the foundation, we have reduced infant mortality to almost $0 \%$ and child malnutrition is at $1.2 \%$, in contrast to the national average of $15 \%$.

In terms of socially complex resources, the organizational culture developed in firms under a sustainable perspective is an important issue, which is difficult for other firms to duplicate. For hotels, the role of organizational culture is essential to sustainability (BH-b, MMR-b). ). "If you want sustainability to work, you have to commit the staff: it is more a question of processes than a financial investment. People need to learn how to separate garbage, to recycle, not to overspend, to turn off the lights, to turn off their computers. It is about creating a culture with $100 \%$ of your staff and involving your guests in this as well” (BH-b). As part of their culture, hotels implement the separation of organic and inorganic waste. They separate recyclables (plastic, aluminum and paper) (FIPF-a, HMM-a, HMM-b, HIF, BH-a, BH-b, MPPP-b, MMR-a, GPVRS-a, ROOP, RC). Some hotels prepare their own compost with waste (HMM-b, GPVRS-a, $\mathrm{RC}, \mathrm{CEP}$ ). In cases where a good public waste collection system is lacking, they engage specialized firms to properly manage the waste (ROOP). To reinforce this culture, hotels 
frequently train their employees about being responsible with water, the environment and energy (MMR-b, ROOP, FAM, RC, BH-a, GPVRS-a). They also establish committees to verify that everything is under control (MMR-b, ROOP): “The people don't do what you expect; the people do what you inspect" (ROOP). Strong commitment from the management to ensure that processes and infrastructures remain under a culture of sustainability is crucial (HMM-b, HIF, CEP, GPVRS-a, FIPF-a, RC): "If the CEO were not interested in sustainability, much of what we do would not be realized. Any new investor is told that the hotel, by design, must use lowenergy consuming bulbs, conserve water from showerheads, things like that ... Yes, that's the project, it has to be in that way. You decide if you are in or not" (CEP).

An important value implicit in the organizational culture of firms really involved with sustainability is the development of social actions (HMM-a). Some hotels support the development of local businesses (HMM-a, ROOP): "We train people from the community to be able to manufacture handicrafts in order to develop their own businesses, and we let them to sell their handcrafts at the hotel. We also have a Spa project which integrates women from the communities; we train and integrate them to work as therapists in the Spas. They are members of cooperatives and they can offer their services at the hotel" (HMM-a).

Hotels also help communities with programs oriented toward the reconstruction of houses or sports facilities and the improvement of existing medical services (BH-b, HMM-a, ROOP): "In health homes we want to support prevention and early detection of diseases. Because here in Mexico people rely heavily on traditional medicine, we wanted to preserve that. In health homes there are allopathic and herbal medicine expert doctors. In fact, we have a botanical garden which has an area of around one hectare, with different species for the preparation of medicinal recipes to supply health homes. From 2004 to 2011 we provided around 20,000 consultations" (HMM-a).

Hotels also collaborate with schools or ONGs by donating money (MMR-a, HIF, FAM, GPVRS-a) or contributing furnishings (microwaves, aspirators, sheets, blankets) that are in good condition but which they don't use anymore or which no longer meet the hotel's standards (HIF, CEP, FIPF-a, MPPP-b, BH-a). They also provide meat for retirement homes, presents for children in orphanages or cleaning supplies (MPPP-a, MPPP-b, GPVRS-a, ROOP).

Most of the hotels involved in sustainability provide training to the community and to schools regarding the importance of environmental preservation, reforestation or hygiene issues (HMMa, HMM-b, HIF, BH-a, MPPP-b, BH-a, ROOP, GPVRS-a, RC). Beach cleaning and reforestation are other social actions promoted by the hotels that have the support of the community and clients (GPVRS-a, GPVRS-b, MPPP-a, BH-a, BH-b, RC).

Hotels also seem interested in cultural preservation (MPPP-a, GPVRS-a, RC). They try to involve the employees: "In November each department puts up an altar for the dead, and in December we hold a contest of piñatas developed by our employees" (MPPP-a), as well as committing their clients: "At the entrance to the hotel we have a giant poster where we explain the Huichol culture and the importance of preserving it. The hotel gives access to the Huichol community to sell their handicrafts here" (GPVRS-a).

In coherence with their organizational culture, hotels encourage and support sustainability in their relationships with suppliers (CEP, HMM-a, HMM-b, BH-a, BH-b MMR-a, MMR-b, FAM, MPPP-a, MPPP-b, ROOP, HIF, MMR-b, RC). Hotels try to convince their suppliers to adopt sustainable practices. Suppliers must be environmentally friendly (BH-a, CEP, MPPP-a, ROOP, HMM-b): "As we are an important hotel chain, we said to our supplier of soap and shampoo 
that if he wanted continue to have a commercial relationship with us, he had to change from plastic to biodegradable packaging. He changed the packaging of his products because of us. We also agreed to send plastic containers back to our natural orange juice supplier to be reused. Now our suppliers are always proposing new products that encourage sustainability. I think we even changed their organizational culture; we made them aware of sustainability" (CEP). "Our pest-control supplier is now certified as a Socially Responsible Company. It emerged from the collaboration with us. They are now providing us with ideas, projects and initiatives focused on sustainability" (MPPP-a). Firms also look for suppliers that avoid pollution for several reasons: 1) because they are local (BH-b, HMM-a, GPVRS-a): "In the past, a supplier sent us meat from the United States. We realized that we were encouraging pollution with that and in order to reduce the environmental impact, we now have a supplier from the region" (HMM-a); 2) because of their processes (HMM-a, FAM, FIPF-b): "If you want to sell me your products, I need to know what you do with the residues. I need to know that you are properly managing them" (FAM); or 3) because of their products: lead-free paints, disposable plates and flatware made from potato peel or bamboo, products that do not damage the ozone layer (CEP, BH-a, HIF, MPPP-b, MMR-b, ROOP, RC).

\section{Organization}

Organization is necessary to provide a source of sustained competitive advantage. In hotels, the establishment of policies and procedures, management control systems and human resources management practices are oriented to achieve sustainability.

Management control systems for energy, water and gas consumption are implemented in most of the hotels interviewed (FIPF-a, FIPF-b, HMM-a, HMM-b, ROOP, CEP, FAM, HIF, BH-a, BH-b, MPPP-a, MPPP-b, MMR-a, MMR-b, ROOP, GPVRS-a, RC, FAM, BH-a, BH-b, RC). To facilitate the control of sustainability, hotels establish teams under the leadership of one person. Most of the time these teams area called "green teams." Every month, the team leaders organize meetings to follow up on the results of sustainability efforts and the teams decide whether improvements are necessary (BH-a, BH-b, FIPF-a, FIPF-b, GPVRS-a, HMM-a, MPPP-a, MPPP-b, MMR-b, R0OP). These follow-up meetings have several advantages for hotels: employees get involved, interesting suggestions to reduce energy, gas or water consumption emerge from employees and improvements to recycling procedure are proposed (HIF, HMM-b, BH-a, BH-b ROOP, RC, MPPP-a, MPPP-b, GPVRS-a, RC, FAM, GPVRS-a). In the hotels, there are different well-established formal policies and procedures that come down from headquarters. They indicate, for example, how to clean, what kind of products to use, what kind of energy-saving light bulbs to use, what to do with dangerous residues, when to schedule fumigations (CEP, FIPF-a, FIPF-b, MPPP-a, MPPP-b, MMR-a, MMR-b, ROOP, GPVRS-a, RC, FAM, BH-a, BH-b, RC, HMM-b, HIF, FAM). Most of those procedures and policies are validated by certifications related to sustainability (HMM-a, BH-a, BH-b, GPVRS-a, RC, FAM, FIPF-a, MPPP-a, MPPP-b, ROOP, RC, CEP, HMM-b, HIF, FAM).

Human resources management practices focused on sustainability are also present in the hotels. In terms of recruitment practices, some hotels have established a policy to recruit mainly local employees (HMM-a, BH-b, GPVRS-a): "We have a strong commitment to hire at least 85\% of employees from the local area” (GPVRS-a). For the internal and external selection of employees, an alignment with sustainability issues is sought out during job interviews (FIPF-a, FIPF-b, MMR-a, MMR-b, HIF, MPPP-a). 
Orientation practices focus on a sustainable vision, mission and culture for the firm, as well as the importance of the proper use of resources and sustainable best practices (HMM-a, HMM-b, MPPP-a, MPPP-b, MMR-a, MMR-b, ROOP, GPVRS-a, HIF, BH-a, BH-b, ROOP, RC). Training practices are fundamental for hotels to commit employees and make them aware of sustainability. Training courses are planned yearly, and the courses are offered at least every month. Training is done internally (mainly by the green team leader) and externally (by the certification agency). Subjects covered in courses may include, for example, English, chemical management, food preparation, waste separation, compost elaboration, management of hazardous waste and child sexual exploitation (CEP, FAM, FIPF-a, FIPF-b, HMM-a, HMM-b, HIF, BH-a, BH-b, MPPP-a, MPPP-b, MMR-a, MMR-b, ROOP, GPVRS-a, GPVRS-b, RC).

Some hotels use special recognition practices to acknowledge the commitment of their employees to sustainability. They establish internal awards (diplomas and publication of the best sustainable employee ideas in bulletins or on blackboards) for so-called "green champions" (HIF, HMM-a, MPPP-a, MMR-a, MMR-b, GPVRS-a, GPVRS-b, RC).

Compensation practices encourage sustainability in hotels. Some hotels that separate waste let their employees to keep the money obtained from the sale of cans, plastic and paperboard (CEP, FIPF-a, FIPF-b): "With the sale of recyclables, maids see the economic benefit of separating the trash" (CEP). Other hotels use the money to organize parties and give presents to employees and employees' children (HMM-a, MMR-b). One hotel gives annual economic bonuses to managers if they attain their objectives in sustainability issues (MMR-b).

In hotels, information and communication practices are crucial to get the support of employees for sustainability. Information and communications may run top-down: hotels use posters, videos, internal newspapers, intranet or blackboards to post information about waste separation, how to handle hazardous waste, compost, nutrition issues and general information about sustainability issues (FAM, FIPF-a, HMM-a, HMM-b, HIF, BH-a, BH-b, MPPP-a, MPPP-b, MMR-a, MMR-b, ROOP, RC). Information and communications also work side by side: hotels establish daily meetings between the managers of different departments to present reports about sustainability issues (FIPF-a, FIPF-b, HMM-a, ROOP, GPVRS-b, RC). Others establish bottom-up information and communication practices, using mailboxes to collect employee's complaints and suggestions (GPVRS-b, RC).

\section{Discussion and conclusions}

Understanding how sustainability can be strategic for the hotel industry is important. The VRIO framework is useful to discover "valuable, rare and costly-to-imitate resources, and then exploit these resources through their organization" (Barney, 1995: 60) for hotel sustainability.

According to the interviews, the firms involved in sustainability consider it to be valuable not only because of the benefits in terms of savings, but also especially in terms of reputation. Being considered as a green hotel or the hotel with the most sustainable certifications establishes a reputation among clients that is a source of competitive advantage (Russo, and Fouts, 1997; Falkenberg and Brunsael, 2011; Jones et al., 2014).

As we can perceive from the interviews, a firms' resources for sustainability are a question not only of individuals but also of teams. In several cases, leaders (because of their real commitment to sustainability) can influence the sustainable behavior of employees. Most of the 
time, interviewees reported that they used teams to manage sustainability. Team-based organization seems to be central for sustainability because it involves "heterogeneous but complementary resources, a high degree of task and outcome interdependence, and the potential for supper-additive outcomes" (Foss and Lindenberg, 2012: 371). In addition, teambased organization permits collaborative activities that create joint motivation to achieve sustainability goals (Lindenberg and Foss, 2011; Foss and Lindenberg, 2012). In order to commit and motivate teams cognitively regarding sustainability, motivational and symbolic management (mainly coming from the leader) is needed primarily. It is also important to maintain a specific organizational design regarding recognition-based reward structures (increasing team members' feelings of organizational care and support) and tasks (requiring for teams to be well organized and to control and follow up on the results in terms of sustainability) (Lindenberg and Foss, 2011; Lawrence and Maitlis, 2012; Foss and Lindenberg, 2012). This means that, even if we have a special leader in a given organization, if teams are not motivated and committed, and organization systems are not efficient, sustainability will not constitute a source of competitive advantage (Barney and Wright,. 1997; Lindenberg and Foss, 2011; Barney et al., 2012; Foss and Lindenberg, 2012; Lawrence and Maitlis, 2012).

A firm's unique personality, experiences and relationships are difficult to imitate (Barney and Wright, 1997; Barney et al., 2012). Hotels that are established given unique historical circumstances (because of their geographical location or after a natural disaster), which led them naturally to sustainability, have experiences that other firms could not have. The experiences and relationships developed due to their commitment to sustainability, as well as the creation and support of foundations or environmental groups, are a source of a non-easily imitable competitive advantage.

As a part of socially complex resources, organizational culture (a costly-to-imitate resource) influences how sustainability is implemented in organizations (Barney and Wright, 1997; Russo, and Fouts, 1997; Linnenluecke, and Griffiths, 2010; Barney et al., 2012). As the managers we interviewed explained, in the hotels there are behavioral rules, norms, shared values, ideologies and beliefs that support sustainability. Hotels establish specific rules about relationships with suppliers; there are strict norms about waste separation and the use of energy and water; shared values are created through training and the development of social actions. They take care of local communities and encourage local businesses. As part of their culture, hotels also believe in the importance of cultural preservation and taking care of the environment. The importance that the hotels under study give to the development of an organizational culture that reinforces sustainability is not the result of a coincidence. The role of organizational culture in sustainability is well established in a number of studies: it is usually cited as the main reason for the failure of organizational change projects involving sustainability (Cameron and Quinn, 2006; Linnenluecke, and Griffiths, 2010).

Following the literature, human resources management practices are crucial to producing sustainable competitive advantage (Pfeffer, 1995; Youndt, Snell, Dean and Lepak, 1996; Wright, Dunford, and Snell, 2001; Chang and Huang, 2005; Guest, 2011; Barney et al., 2012). As was reported by interviewees, specific human resources practices concerning recruitment, selection, orientation, training, recognition, compensation and benefits, and information and communication must be designed to encourage sustainability efforts among employees. These bundles of specific human resources practices are also called high-performance work practices (HPWPs) (Posthuma, Campion, Masimova, and Campion, 2013). In firms, these practices can be perceived as a signal of support that the firms are prepared to offer to upgrade attitudes and behaviors concerning employees' commitment to sustainability. This is why several authors

14 - IESE Business School-University of Navarra 
considered the role of human resources practices as central in the pursuit of sustainable organizations (Jabbour and Santos, 2008; Kramar, 2014). However, as Fenwick and Bierema (2008) demonstrated, human resources (HR) managers may maintain a certain distance, or even a disconnection, from a firm's sustainability commitments. It is also important to note that, according to numerous studies, individual human resources practices can only lead to a temporary competitive advantage; it is the system of HPWPs that has stronger effects on competitive advantage (Barney and Wright,. 1997; Combs, Liu, Hall and Ketchen, 2006).

After reading our results, hotel managers have several courses of action at their disposal for designing human resource management practices that can really influence employees' commitment to sustainability, and, consequently, the competitive advantage of their firms. The challenge here is, first, for firms to be able to involve HR managers in sustainability; and, second, for HR managers to be able to develop adequate systems of HPWPs in synergy with their sustainability goals.

This research represents a contribution compared to the existing studies, which have almost never focused on sustainability in hospitality and the importance of internal resources for obtaining competitive advantages (Simão, 2010; Tavitiyaman et al., 2011, Harrington, et al., 2014).

There are some limitations in this research. One limit of our study concerns the limited sample of interviews realized: future research must include larger samples to generate a wider overview of sustainability management in hotels. Our main objective was to explore and understand how resources' attributes are present in a hotel's sustainability practices, rather than establishing generalizations. We only examine the situation of sustainability in hotels in Mexico; future research should consider other countries using the VRIO framework. Another interesting issue to explore would be to make a comparison using the VRIO framework, between hotels where HR managers are involved in sustainability and hotels where HR managers are not concerned with sustainability (Fenwick and Bierema, 2008). 


\section{References}

Adams, W. M. 2006. The Future of Sustainability: Re-thinking Environment and Development in the Twenty-first Century. Report of the IUCN Renowned Thinkers Meeting, 29-31 January 2006, available at: http://cmsdata.iucn.org/downloads/iucn_future_of_sustanability.pdf, accessed January 6th, 2015.

Amit, R., \& Schoemaker, P. J. 1993. Strategic assets and organizational rent. Strategic Management Journal, 14(1): 33-46.

Amsler, S. S. 2009. Embracing the politics of ambiguity: Towards a normative theory of "sustainability". Capitalism Nature Socialism, 20(2): 111-125.

Barney, J. 1991. Firm resources and sustained competitive advantage. Journal of Management, 17(1): 99-120.

Barney, J. B. 1995. Looking inside for competitive advantage. The Academy of Management Executive, 9(4): 49-61.

Barney, J. B. 1997. Gaining and Sustaining Competitive Advantage. Reading, MA: AddisonWesley.

Barney, J. B., \& Wright, P. M. 1997. On becoming a strategic partner: The role of human resources in gaining competitive advantage, CAHRS Working Paper \#97-09. Ithaca, NY: Cornell University, School of Industrial and Labor Relations, Center for Advances Human Resource Studies: 1-25.

Barney, J. B., Della Corte, V., Sciarelli, M., \& Arikan, A. 2012. The role of resource-based theory in strategic management studies: managerial implications and hints for research. In G. Battista Dagnino (Ed.), Handbook of Research on Competitive Strategy: 109-146. UK-USA: Edward Elgar.

Barney, J., Wright, M., \& Ketchen, D. J. 2001. The resource-based view of the firm: Ten years after 1991. Journal of Management, 27(6): 625-641.

Branco, M. C., \& Rodrigues, L. L. (2006). Corporate social responsibility and resource-based perspectives. Journal of Business Ethics, 69(2): 111-132.

Cameron, K. S., \& Quinn R. E. 2011. Diagnosing and changing organizational culture: Based on the competing values framework. John Wiley \& Sons.

Chang, W. J. A., \& Huang, T. C. 2005. Relationship between strategic human resource management and firm performance: A contingency perspective. International Journal of Manpower, 26(5): 434-449.

Combs, J., Liu, Y., Hall, A., \& Ketchen, D. 2006. How much do high-performance work practices matter? A meta-analysis of their effects on organizational performance. Personnel Psychology, 59(3): 501-528. 
European Commission (2009). A guide to communication about CSR, available at: http://ec.europa.eu/enterprise/policies/sustainable-

business/files/csr/campaign/documentation/download/guide_en.pdf, accessed December, 17, 2014.

Falkenberg, J., \& Brunsæl, P. 2011. Corporate social responsibility: A strategic advantage or a strategic necessity? Journal of Business Ethics, 99(1): 9-16.

Fenwick, T. \& Bierema L. 2008. Corporate social responsibility: issues for human resource development professionals. International Journal of Training and Development, 12(1): 24-35.

Foss, N. J., \& Lindenberg, S. 2012. Teams, team motivation, and the theory of the firm. Managerial and Decision Economics, 33(5-6): 369-383.

Grant, R. M. 1988. On "Dominant Logic", relatedness, and the link between diversity and performance. Strategic Management Journal, 9(6): 639-642.

Grant, R. M. 1991. The resource-based theory of competitive advantage: implications for strategy formulation. California Management Review, 33(3): 114-135.

Guest, D. E. 2011. Human resource management and performance: still searching for some answers. Human Resource Management Journal, 21(1): 3-13.

Harrington, R. J., Chathoth, P., Ottenbacher, M., \& Altinay, L. 2014. Strategic Management Research in Hospitality and Tourism: Past, Present and Future. International Journal of Contemporary Hospitality Management, 26(5): 778-808.

Jabbour, C. J. C., \& Santos, F. C. A. 2008. The central role of human resource management in the search for sustainable organizations. The International Journal of Human Resource Management, 19(12), 2133-2154.

Jones, P., Hillier, D., \& Comfort, D. 2014. Sustainability in the global hotel industry. International Journal of Contemporary Hospitality Management, 26(1): 5-17.

Kramar, Robin. 2014. Beyond strategic human resource management: Is sustainable human resource management the next approach? The International Journal of Human Resource Management, 25(8): 1069-1089.

Lawrence, T. B. \& Maitlis, S. 2012. Care and possibility: Enacting an ethic of care through narrative practice. Academy of Management Review. 37(4): 641-663.

Lindenberg, S., \& Foss, N. J. 2011. Managing joint production motivation: The role of goal framing and governance mechanisms. Academy of Management Review, 36(3): 500-525.

Linnenluecke, M. K., \& Griffiths A. 2010. Corporate sustainability and organizational culture. Journal of World Business, 45(4): 357-366.

Linnenluecke, M. K., \& Griffiths, A. 2010. Corporate sustainability and organizational culture. Journal of World Business, 45(4): 357-366.

Peng, M. (2013). Global Strategy. Mason OH: Cengage Learning.

Pfeffer, J. 1995. Producing sustainable competitive advantage through effective management of people. Academy of Management Executive, 9(1): 55-69. 
Porter, M., \& Kramer, M. 2006. Estrategia y Sociedad. Harvard Business Review, 84(12): 42-56.

Posthuma, R. A., Campion, M. C., Masimova, M., \&t Campion, M. A. 2013. A High Performance Work Practices Taxonomy Integrating the Literature and Directing Future Research. Journal of Management, 39(5): 1184-1220.

Prairie, P. 2012. A Critical Look at Hotel Sustainability, available at: http://www.huffingtonpost.com/patti-prairie/a-critical-look-at-hotel-_b_1471188.html, accessed December, 17, 2015.

Russo, M. V., \& Fouts, P. A. 1997. A resource-based perspective on corporate environmental performance and profitability. Academy of Management Journal, 40(3): 534-559.

Simão, J. 2010. An extended VRIO model as a framework for sustainable tourism planning. In C. A. Brebbia \&t F. D. Pineda (Eds.), Sustainable Tourism IV (Vol. 139): 87-97. Southampton, UK: WIT Press.

Tavitiyaman, P., Qu, H., \& Zhang, H. Q. 2011. The impact of industry force factors on resource competitive strategies and hotel performance. International Journal of Hospitality Management, 30(3): 648-657.

Todorov, V. I., \& Marinova, D. 2009. Models of sustainability. 18th World IMACS Congress, Cairns, Australia, 1216-1222.

United Nations General Assembly. 1987. Report of the World Commission on Environment and Development: Our Common Future. Transmitted to the General Assembly as an Annex to document A/42/427 - Development and International Co-operation: Environment, available at: http://www.un-documents.net/wced-ocf.htm, accessed January 6th, 2015.

Wright, P. M., Dunford, B. B., \& Snell, S. A. 2001. Human resources and the resource based view of the firm. Journal of Management, 27(6): 701-721.

Youndt, M., Snell, S. A., Dean, J. W. \& Lepak, D. P. 1996. Human resource management, manufacturing strategy, and firm performance. Academy of Management Journal, 39(4): 836-366. 